patients had an osteoporosis (54.8\%): six cases of $\mathrm{HCV}$, three cases of HBV, five cases of PBC, two cases of $\mathrm{AlH}$ and one case of PSC. Osteoporosis is most common in postmenopausal women with significant correlation $(p<0,001)$. Hyperbilirubinaemia and increased Gamma Glutamyl Transferase (GGT) were significantly correlated with osteoporosis $(p<0.05)$. However, there was no significant correlation between osteoporosis and body mass index or the Child-Pugh score.

Conclusion: In our study, $54.8 \%$ of cirrhotic patients who have had a $\mathrm{BMD}$, had an osteoporosis. It was more frequent among postmenopausal women with hyperbilirubinaemia and increased GGT. The systematic realization of BMD in these patients could contribute to better management. Disclosure of Interests: None declared DOI: 10.1136/annrheumdis-2019-eular.8037

\section{AB0857 DENSITOMETRY VALUES CHANGE WHEN STOPPING DENOSUMAB}

Urionaguena Irati ${ }^{1}$, P Sandra. Chinchilla Gallo ${ }^{2}$, Sandra Hernandez Gomez ${ }^{1}$, Jose Francisco Garcia Llorente ${ }^{1}$, Izaskun Aizpurua Manso ${ }^{1}$, Nuria Vegas Revenga ${ }^{1}$.

${ }^{1}$ Galdakao-Usansolo Ospitalea, Rheumatology, Galdakao-Usansolo, Spain;

${ }^{2}$ University of the Basque Country, Bilbao, Spain

Background: Denosumab (DMAB) withdrawal without subsequent bisphosphonate treatment seems to be related to a rebound effect: a rapid decrease in mineral density in bone densitometry (DEXA). However, evidence is scarce.

Objectives: To analyze DEXA values in patients who have stopped DMAB without subsequent treatment and to detect possible factors associated.

Methods: Unicentric observational study. We included patients with osteoporosis (OP) who attended our rheumatology clinic from May 2017 to December 2018, who had stopped DMAB without any further treatment. Demographic data, risk factors for OP (smoking, age of menopause, previous fractures, chronic corticotherapy), data related to calcium and vitamin $D$ analogues supplementation, previous OP treatment and durantion of active treatment with DMAB were collected; as well as DEXA data (last DEXA while on DMAB and inmmmediate DEXA after its withdrawal, no more than 3 years later). For the statistical analysis, means, standard deviations, frequencies and percentages are reported accordingly. Paired Student's $T$ test has been used to analyze medias in both DEXAs, and chi square for comparisons when appropriate.

Results: 39 patients (38 women) age $70.17 \pm .4$, menopause at $46 \pm 4.07$ years, $37(94 \%)$ never used tobacco, $25(64 \%)$ suffered some fracture before treatment with DMAB, $17(43 \%)$ received previous bisphosphonates, $5(13 \%)$ teriparatide and $7(18 \%)$ strontium ranelate. The average duration of DMAB use was $2 \pm 0.86$ years, onset at $61 \pm 7.34$ years. Standard deviations (T score) of DEXA values worsened significantly $(p<0.001)$ in all the locations: femur -0.28 (IC95\% -0.36 to -0.19 ), columnL1 -0.43 (IC95\% -0.30 a -0.56 ), columnL2 -0.44 (IC95\% -0.25 to -0.62 ) columnL3 -0.40 (IC95\% -0.22 to -0.59 ) columnL4 -0.52 (IC95\% $-0,33$ to -0.72 ) columnL1-L4 -0.48 (IC95\% -0.33 to -0.64 ) (table 1). We analyzed the decrease in T-scores alongside the other variables, obtaining a proportionally inverse relation between duration of $D M A B$ use and this reduction (table 2). Given that DMAB use in one patient was several standard deviations above the mean (12 yrs), her data where excluded for analysis.

Conclusion: DMAB withdrawal without subsequent antiresorptive treatment produces a rapid decrease in DEXA values in our patients. This phenomenon appears to diminish in patients who have received DMAB for a longer period.

\section{REFERENCES}

[1] M. B. Zanchetta, J. Boailchuk,F. Massari,F. Silveira,C. Bogado and J. R. Zanchetta. Significant bone loss after stopping long-term denosumab treatment: a post FREEDOM study. Osteoporos Int(2018) 29:41-47

[2] Olivier Lamy, Delphine Stoll, Bérengère Aubry-Rozier, Elena Gonzalez Rodriguez. Stopping Denosumab. Current Osteoporosis Reports. Published online Jan. 2019

[3] Chapurlat R, Effects and Management of Denosumab Discontinuation, Joint Bone Spine (2018).
Abstract AB0857 Table 1. Comparison T-score DEXA previous to DMAB withdrawal $\left(1^{\text {st }}\right.$ DEXA) and afterwards (2 ${ }^{\text {nd }}$ DEXA)

\begin{tabular}{lccc}
\hline & $\begin{array}{c}\text { Mean T-score } \pm \\
\text { SD }^{+} \\
1^{\text {st }} \text { DEXA }\end{array}$ & $\begin{array}{c}\text { T-score Media } \pm \\
\text { SD }^{+} \\
2^{\text {nd }} \text { DEXA }\end{array}$ & $\begin{array}{c}\text { Media difference between } 1^{\text {st }} \text { and } 2^{\text {nd }} \\
\text { DEXA }\end{array}$ \\
\hline Total & $-1.46 \pm 0.85$ & $-1.74 \pm 0.87$ & $-0.28^{*}$ \\
Femur & & & \\
Column L1 & $-2.16 \pm 0.82$ & $-2.59 \pm 0.75$ & $-0.43^{*}$ \\
Column L2 & $-2.42 \pm 0.81$ & $-2.87 \pm 0.75$ & $-0.44^{*}$ \\
Column L3 & $-2.01 \pm 0.82$ & $-2.42 \pm 0.89$ & $-0.40^{*}$ \\
Column L4 & $-2.04 \pm 1.10$ & $-2.57 \pm 1.06$ & $-0.52^{*}$ \\
Column L1- & $-2.12 \pm 0.76$ & $-2.61 \pm 0.71$ & $-0.48^{*}$ \\
L4 & & &
\end{tabular}

${ }^{*} \mathrm{p}<0.001{ }^{+} \mathrm{SD}:$ Standard deviation

Abstract AB0857 Table 2

YEARS ON DMAB DIVIDED INTO TERTILES * COLUMN L1 L4 SD DIFFERENCE IN TERTILES Crosstabulation

\begin{tabular}{|c|c|c|c|c|c|c|}
\hline-0.60 and more & \multirow[b]{2}{*}{$\begin{array}{l}-0.59 \\
\text { to - } \\
0.30\end{array}$} & \multirow[b]{2}{*}{-0.29 and less } & \multicolumn{3}{|c|}{ Difference L1 L4 in tertiles } & \multirow[t]{2}{*}{ Total } \\
\hline-0.60 and more & & & & & & \\
\hline \multirow{7}{*}{$\begin{array}{l}\text { YEARS ON DMAB } \\
\text { DIVIDED INTO } \\
\text { TERTILES }\end{array}$} & $0-1.95$ & Count & 7 & 5 & 1 & 13 \\
\hline & & $\%$ within & $46.7 \%$ & $50.0 \%$ & $10.0 \%$ & $37.1 \%$ \\
\hline & & $\begin{array}{l}\text { Difference L1 L4 } \\
\text { in tertiles }\end{array}$ & & & & \\
\hline & $1.96-$ & Count & 3 & 5 & 3 & 11 \\
\hline & 2.38 & $\begin{array}{l}\% \text { within } \\
\text { Difference L1 L4 } \\
\text { in tertiles }\end{array}$ & $20.0 \%$ & $50.0 \%$ & $30.0 \%$ & $31.4 \%$ \\
\hline & 2.39 & Count & 5 & 0 & 6 & 11 \\
\hline & $\begin{array}{l}\text { or } \\
\text { more }\end{array}$ & $\begin{array}{l}\text { \% within } \\
\text { Difference L1 L4 } \\
\text { in tertiles }\end{array}$ & $33.3 \%$ & $0.0 \%$ & $60.0 \%$ & $31.4 \%$ \\
\hline \multirow[t]{2}{*}{ Total } & & Count & 15 & 10 & 10 & 35 \\
\hline & & $\begin{array}{l}\text { \% within } \\
\text { Difference L1 L4 } \\
\text { in tertiles }\end{array}$ & $100.0 \%$ & $100.0 \%$ & $100.0 \%$ & $100.0 \%$ \\
\hline
\end{tabular}

Disclosure of Interests: None declared

DOI: 10.1136/annrheumdis-2019-eular.4338

\section{AB0858 MAINLY MEN, AND OLDER PEOPLE, WITH FRAGILITY HIP FRACTURE DO NOT RECEIVE ANTIOSTEOPOROTIC TREATMENT}

Paloma Vela-Casasempere $^{1,2,3}$, Marta Elvira ${ }^{2}$, Antonio Palazon Bru², Silvia Gomez-Sabater ${ }^{3}$, Rocio Caño-Alameda ${ }^{3} .{ }^{1}$ ALICANTE UNIVERSITY GENERAL HOSPITAL, RHEUMATOLOGY, ALICANTE, Spain; ${ }^{2}$ Miguel Hernandez University, Clinical Medicine, San Juan, Spain; ${ }^{3} I S A B I A L$, Alicante, Spain

Background: Osteoporotic hip fractures have a profound impact on the physical health and psychosocial wellbeing of patients, with considerable economic implications. More than $20 \%$ of individuals experience a subsequent hip fracture in the following year $(1,2)$. Although there are effective treatments in the prevention of fractures, the proportion of patients who start treatment after a fragility fracture is low, having decreased in recent years (3)

Objectives: The aim of the study is to know the percentage of patients who received medical treatment for osteoporosis after a fragility hip fracture in our health department. Secondary, we want to know the mortality and re-fracture rates two years after the fracture.

Methods: Cross-sectional retrospective observational study. Patients dis charged during 2015 with diagnosis of "Fragility Hip Fracture" were reviewed, data collected through electronic medical record. Variables: sex; age; age and date of death; treatment (calcium, vitamin D or antiosteoporotic drugs) before and after discharge; Fragility fracture before and after hospital discharge. Statistical methods: absolute and relative frequencies for qualitative variables, means and standard deviations for quantitative. Associations between variables were studied using Chi square and T-student test. 